\title{
Designing an Interactive Gravestone Display
}

\author{
Jonna Häkkilä \\ University of Lapland \\ Rovaniemi, Finland \\ jonna.hakkila@ulapland.fi
}

\author{
Ashley Colley \\ University of Lapland \\ Rovaniemi, Finland \\ ashley.colley@ulapland.fi
}

\author{
Matilda Kalving \\ University of Lapland \\ Rovaniemi, Finland \\ matilda.kalving@ulapland.fi
}
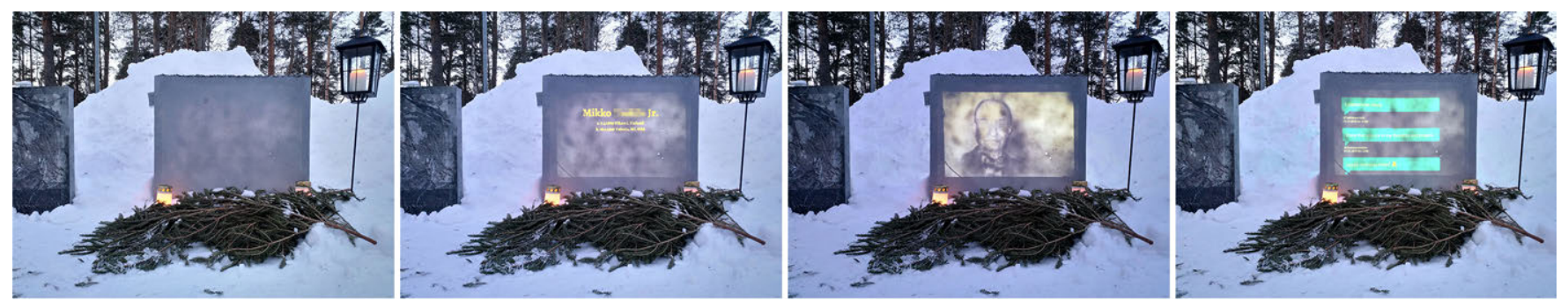

Figure 1: Gravestone display showing as selection of the visualizations evaluated in the user study

\begin{abstract}
HCI research surrounding death has largely focused to an individual's digital remains, with relatively less attention paid to physical memorials, such as graves. We present a prototype interactive gravestone, which aims to blend in seamlessly with traditional stone gravestones. Based on RFID cards inserted into the gravestone, different content is displayed on the gravestone surface. We evaluated the concept though a focus group exploring different types of content displayed on the gravestone, ranging from an individual name, to photographs and an interactive visitors book. Our salient findings show the concept was positively received as a memorial, when designed to match with the dignity of the context.
\end{abstract}

\section{CCS CONCEPTS}

- Human-centered computing $\rightarrow$ Human computer interaction (HCI).

\section{KEYWORDS}

graveyard, cemetery, death, family histories, remembrance, cultural heritage, pervasive displays, user experience

\section{ACM Reference Format:}

Jonna Häkkilä, Ashley Colley, and Matilda Kalving. 2019. Designing an Interactive Gravestone Display. In Proceedings of the 8th ACM International Symposium on Pervasive Displays (PerDis '19), June 12-14, 2019, Palermo, Italy. ACM, New York, NY, USA, 7 pages. https://doi.org/10.1145/3321335. 3324952

Permission to make digital or hard copies of all or part of this work for personal or classroom use is granted without fee provided that copies are not made or distributed for profit or commercial advantage and that copies bear this notice and the full citation on the first page. Copyrights for components of this work owned by others than the author(s) must be honored. Abstracting with credit is permitted. To copy otherwise, or republish, to post on servers or to redistribute to lists, requires prior specific permission and/or a fee. Request permissions from permissions@acm.org.

PerDis '19, fune 12-14, 2019, Palermo, Italy

(ㄷ) 2019 Copyright held by the owner/author(s). Publication rights licensed to ACM ACM ISBN 978-1-4503-6751-6/19/06 . .\$15.00

https://doi.org/10.1145/3321335.3324952

\section{INTRODUCTION}

In olden days, families typically remained living in the same area for generations, and village or town graveyards included large family graves. The proximity of the living descendants enabled easy access to the graves, which were frequently visited and cared for. In today's world, families are distributed over long distances, and family ties have become looser. The old family graves may be geographically far away, and visiting them practically impossible. In urban environments, the limited availability and high cost of physical burial plots presents further challenges to physical memorial sites [1]. However, traditions of remembrance may still be craved for, and rituals such as placing flowers or lighting candles at a grave may play an important role in family traditions.

Currently, there is much discussion on the 'digital afterlife'. Research has addressed different phenomena related to death in the digital age, such as postmortem social media messages [4], or passing on digital remains after death [26]. Altogether, the practices of remembrance and mourning death are changing in the age of Internet [30]. Some presented digital solutions target to the new forms of remembrance, e.g. preserving a persons digital remains through a Facebook memorial site. Other approaches, such as Eternime [12] aim to create digital avatars of the dead, that relatives can interact with. The topic has also been addressed though science fiction e.g. Black Mirror 'I'll be right back' [20], Real Humans [19] and Altered Carbon [7]. But what happens to physical graveyards in these future visions? The use of QR codes and screens embedded in gravestones showing videos of the deceased has been explored $[13,29]$, but such solutions seem to discard the emotional, cultural and historical importance of the graveyard.

Graveyards are places of remembrance and mourning, but also sites of cultural heritage and family histories. How can we design digital technologies, which maintain the essence of the user experience when visiting a grave, but take an advantage of digital technologies to make them more accessible and have richer content? Our work is motivated:

(1) To enable individuals to experience visiting the grave of a loved one, where the real grave or memorial is inaccessible, 
e.g. due to location, or not available e.g. due to limited burial space.

(2) To explore the design space for providing richer digital content on gravestones, whilst remaining in keeping with the graveyard context.

In this paper, we consider gravestones as pervasive displays, and explore a concept with dynamically changeable content on a gravestone. With pervasive displays invading different spaces of our everyday life $[2,4,18,22]$, graveyards are still locations with little embedded technology, and a novel context to investigate. We present the design, implementation, and user evaluation of an interactive gravestone concept. In contrast to prior work on the topic, we aim to create a solution that is indistinguishable from a traditional stone gravestone and fully in keeping with the graveyard environment. The contribution of our work lies in presenting a novel concept for a dynamic gravestone and in increasing understanding of the possibilities and user perceptions related to digitization in the graveyard. To the best of our knowledge, we are the first to present findings on perceptions towards different content types displayed on gravestones.

\section{RELATED WORK}

Prior works relevant to our topic are those encompassing the broader area of HCI for remembrance and death and the graveyard as a context.

\subsection{Interactive Concepts for Remembrance and Death}

A main focus of research on death in the HCI domain has been towards handing digital remains after an individual's death [23, 27]. Massimi et al. explored how digital artefacts left behind postmortem are used by loved ones as tools for remembrance, highlighting a number of unaddressed problems [23]. Focusing on social media, Brubacker et al. [3] review issues related to inheritance and the legacy contact approach employed by Facebook on memorial pages. In the physical world, ambient displays have been applied for remembrance. For example, as an ephemeral remembrance installation, where lighting a candle triggers photos of a past family member to appear in the background [28], or the Penseive Box, which illuminates on special occasions shared with a deceased loved one [10]. It has also become easier for people to plan their own death and create services for their remaining loved ones [16, 21]. Jamison et al. investigated postmortem messages that are delivered after the sender's death [21]. Hall et al. presented a concept to publish digital memories at the locations the content was created [16].

Considering digitally augmenting gravestones, concepts adding content via smartphone readable $\mathrm{QR}$ codes have been demonstrated $[6,13]$. A variety concepts for gravestones with embedded digital displays has also been demonstrated by commercial organisations ranging from embedding small tablets [29] to large 48" interactive screens [14] (Figure 2, left \& center). Driven by the limited availability and high costs of burial sites in some Asian cities, commercial organisations are now offering graves in virtual cemeteries [9] (Figure 2, right). Another approach provides a communal memorial site, where the deceased are represented by glass Buddha statues, which relatives may visit using a smart access card [1]
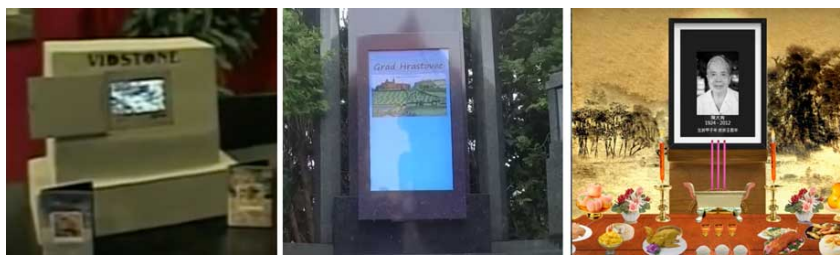

Figure 2: Examples of commercial gravestone display concepts. Left/Center: OLED displays embedded in gravestones. Right: Gravestone in virtual world

\subsection{Graveyards as Cultural Heritage}

Research has also considered graveyards as historical cultural heritage sites, and explored digital solutions for connecting visitors with the past [11]. As part of the meSch project, Ciolfi and Petrelli [11] presented concepts such as a digital guide book and Augmented Reality binoculars, to provide graveyard visitors with more informed experiences. The future cemetery project in Bristol, UK, utilized projection on objects within the cemetery, but focused more on artistic and cultural heritage aspects than individual mourning [8]. Häkkilä et al. [15] presented a graveyard navigator smartphone application to support visitors' navigation at cemeteries, and explored concept of visualizing family trees as links between graves.

\section{GRAVESTONE DISPLAY}

\subsection{Concept}

To address our defined research area we created a prototype gravestone display to act as a probe in user evaluation.

Our gravestone display concept aimed to address two broad use cases, 1) displaying additional content related to an individual's grave 2) a 'shared display' able to present information on different deceased, e.g. depending on the visitor. Prior works have presented OLED screens embedded in gravestones, which are perceived as environment embedded screens, similarly to public displays e.g. in shopping centers. In contrast, our aim was to understand the potential and issues surrounding a display seamlessly integrated into a gravestone, i.e., a gravestone capable to display dynamic content, that was not immediately perceived as being a digital display screen.

\subsection{Design and Implementation}

Based on our motivation, we aimed to create a prototype that would, as far as possible, appear to be an authentic stone gravestone. Our implementation utilized back-projection on a screen modeled to look like a gravestone. The mockup gravestone was built from a wooden frame covered with a transparent acrylic sheet, which was then painted using a stone effect paint (see Figure 1). To complement the effect, gravel was added to the top of the gravestone to provide the effect of rough-cut stone. As the light source, we used a shortthrow projector placed approximately $40 \mathrm{~cm}$ behind the mockup gravestone.

When planning the method of interaction with the gravestone we considered a variety of approaches, e.g. using a mobile app. However, aiming to maintain the physicality of our concept, we selected to control the gravestone display though RFID based cards 


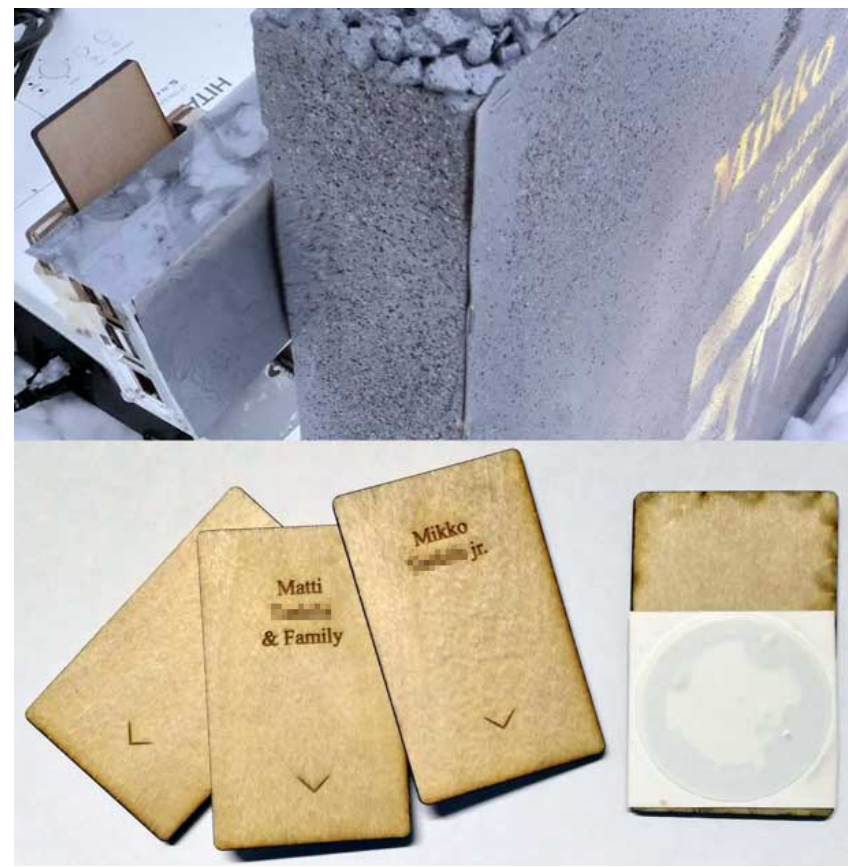

Figure 3: Closeup of the RFID tag reader integrated into the gravestone and examples of the wooden cards used to trigger display content

(Figure 3, bottom). Conceptually, each card represented a deceased individual and, in-keeping with the natural graveyard context, the cards were laser-cut and engraved from birch plywood. RFID tags were attached to the back of the wooden cards. The prototype functionality was implemented using a Raspberry Pi and a Mifare RC522 RFID reader board which were attached to the gravestone (Figure 3, top). When inserted in the card reader slot, each RFID card produced a different image, back-projected on the gravestone. In addition, some cards produced a looping sequence of images, with each image being displayed on the gravestone for 6 seconds.

\subsection{Gravestone Content}

Aiming to use the gravestone display as a probe to investigate opinion and drive ideation on the topic, we designed a variety of traditional and exploratory content (Figure 4). To ensure our evaluation addressed the sensitivity of the topic, we considered it important to use information of real deceased individuals. Hence, we utilised family data and images provided by one of our researchers, who's family has actively researched its history. The presented content included, simple gravestone text (A, B), a photograph of the deceased (C), a family tree(D) and related family photographs (E, F). Additionally, views illustrating messaging/chat (G), social media content $(\mathrm{H})$ and the gravestone of famous person $(\mathrm{I})$, were created.

\section{USER STUDY SET-UP}

As our study was explorative, primarily aiming to generate new ideas and understand why exposed issues were important, the focus group method was selected as a suitable approach [24]. Rather than
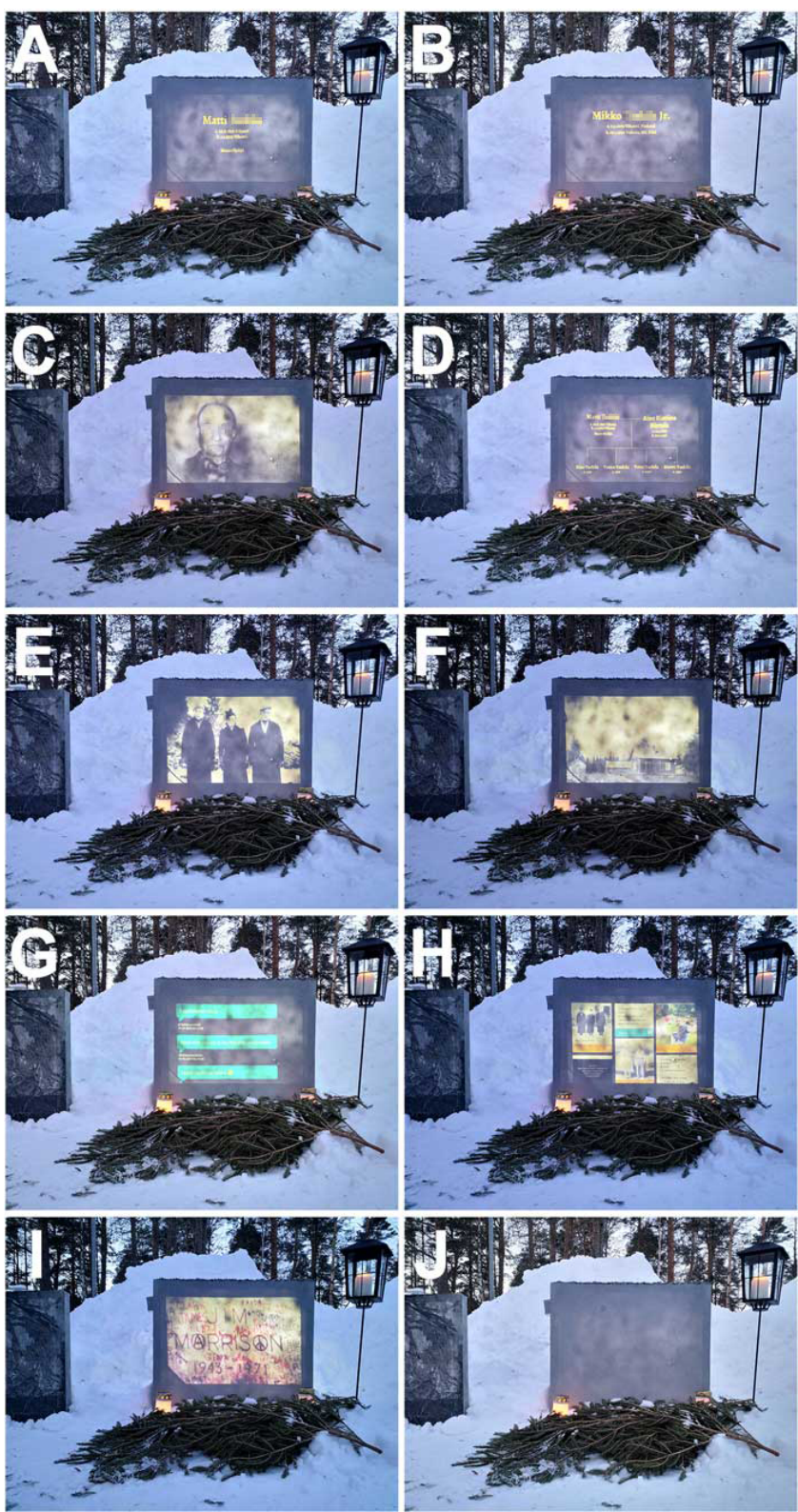

Figure 4: The set of probe display content used in the user study

conduct the study in an actual graveyard, which would have presented ethical challenges, we created a staged outdoor graveyard in the grounds of the university. The 'graveyard' contained 2 mockup gravestones and was constructed so that it resembled a local graveyard with the typical context of nature and solitude (Figure 1). To support the staging, we included a grave lantern, candles and laid tree branches over the grave (as is the local custom). The study was documented through audio recording, written notes taken by a researcher, and photographs. Three researchers led and facilitated the user study session. 


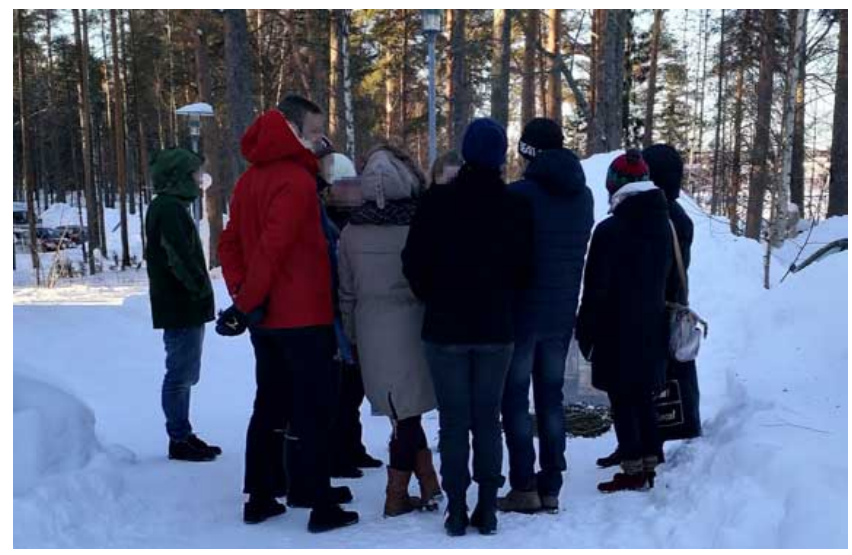

Figure 5: Focus group participants evaluating the gravestone display concept

At the beginning of the study, the participants completed a consent form and a background questionnaire (indoors). As an introduction, it was explained that the study focused on new concepts around graves and family histories, and thinking aloud was encouraged. To stimulate the atmosphere one participant was asked to light a candle, which was to be carried to the grave. Then, the group was led outdoors, where a $50 \mathrm{~m}$ walk took them to the staged grave site (Figure 5). On arrival, a simple gravestone text (Figure 4A) was already visible on the stone. The concept of dynamically changing the gravestone display by inserting an smart card into the gravestone was described to the participants. By inserting different smart cards the participants were shown the following sets of content, and the facilitator encouraged group discussion on based on the stimulus.

- Gravestone text (Figure $4 \mathrm{~A}$ )

- Text with photo

- Person 2 text (B), photo (C), family tree (D), photo of his children (E), photo of his house (F); views circulating

- Visitor book view 1) on-site visitors, 2) remote people's entries, and 3) a chat window to interact with an Artificial Intelligence (AI) representation of the deceased $(\mathrm{G}, \mathrm{H})$

- Gravestone of a famous person (I)

At the end of the test, the original text (A) was returned to the gravestone when leaving the grave site. When back indoors, the participants completed an end questionnaire, which included four questions on the experience, and an AttrakDiff [17] rating for the overall interactive gravestone concept.

Eight participants were recruited from the local university (4 male, 4 female), in the age groups 18-25 (five) and 26-35 (three). Seven out of eight stated that they were interested in family history. The most common reasons the participants visited a graveyard were 1) remembrance of relatives and friends $(8 / 8), 2)$ to light a candle or bring flowers $(4 / 8), 3)$ interest in historical environments $(3 / 8)$, and 4$)$ because graveyards were peaceful places for walking $(3 / 8)$.

\section{FINDINGS}

\subsection{Gravestone Style and Design}

Style and design were perceived as very important factors in the context of gravestones and remembrance of the dead. Especially, people felt that the design and style should be dignified and respectful, and the gravestone or memorial design should give an impression of value, and something that is long lasting. Frequently, participants commented that the gravestone concept did not feel or look respectful enough, e.g. the photograph appearing and disappearing. Although the gravestone display simulated the style of a traditional gravestone, participants did not consider it as respectful and proper as real "golden letters in stone". One participant stating, "The traditional tombstone has dignity when it is engraved." (\#7).

The longevity of the gravestone was emphasized in the group discussion, and concerns about modern technology and its inability to last for decades or centuries were raised. Participants stating, "The gravestone is almost the only thing we leave behind."(\#5) and "A gravestone is forever, even if the city collapses, but this won't last forever." (\#2). In addition, concerns of malfunctions were verbalized: "What if it doesn't work when someone goes there, and they leave disappointed?" (\#3).

There was positive conversation about projecting digital content in the context of cemeteries that were crowded with graves, or urns. In these environments, where each person has only a small placard with his/her name amongst numerous similar placards, seeing something more when visiting was considered a nice idea, comments e.g., "It would bring more value to the placard."(\#3) and "It would make it feel more individual." (\#5).

\subsection{Content and Interaction}

Participants desired that the interaction with (or at) the interactive gravestone would be peaceful in pace, and give a respectful impression. The feeling of a 'slide show' was despised as not fitting to the context or giving a respectful experience. The displayed photographs were commented in both positive and negative senses, e.g, "If it's a memorial stone, the picture suits it. Personally I don't like gravestones that have a picture on them." (\#7) and "They are less dignified." (\#5). Whilst in the positive sense, "But to that [digital gravestone] it kind of suits, because it's not a real grave." (\#6). It was also commented that "A picture might suit a memorial site for a grave that is far away." (\#1). On the other hand, it was also commented that there was value in seeing old pictures, as they told something of the deceased person, giving context and enabling connecting with them. For instance, it was commented, "It would be different [better] to, instead of saying to kids 'here is your great-grandmother', you could actually say 'see [a photo], this is her' ". (\#6)

Presenting the family tree was generally seen as an interesting option, but not fitting to be projected on the gravestone. Participants stating, "If it's relatives you don't know that well, it would be a great way to get the information, but is a graveyard the right place for family research?" (\#2) and "I'm thinking about what we leave after us when we die, this might be a nice addition. But it doesn't suit a gravestone."(\#7). It was also commented that if one was a regular visitor at a graveyard, it would be interesting to browse through a family tree, but not at the grave itself. 
The change of the content with the RFID cards was well understood and perceived as intuitive, but the timing of the interaction at the grave was criticized. It was suggested that the recognition enabling presenting personalized content should have happened earlier, before the visitor came into the vicinity of the gravestone itself - "The picture should be the correct one already when the person enters the cemetery, he should not see the change. Like a keyless car. Without any visible interactivity, just as a passive stone." (\#7).

In the discussions, some concerns related to potential conflicts with multiple simultaneous visitors were raised. Comments, e.g., "[It would be] awful if two people turned up at the same time wanting to see different graves and then it starts flickering between them." (\#6), continuing, "Yeah, if they start arguing which grave should be projected." (\#5). Also the multitude of possible digital gravestones was pondered, "If my relatives that live abroad die, are they projected in multiple cities?" (\#5).

\subsection{Alternative Design Suggestions}

Generally, the participants saw value in the concept, but it was also perceived that the gravestone itself would not be the optimal place for visualizing the content. Other types of solutions were suggested. It was commented that there could be a place next to the grave, or a separate space, where one could see more content related to the deceased for remembrance. For instance there could be a silent room at the graveyard, or next to the memorial plaques. Participants commenting, e.g., "Does it have to be a gravestone? How about if it was like the memorial stones where people go to put candles for people who have been buried far away?" (\#1), or, "What if it was a monolith. A building you could go in to." (\#7). It was also commented, "In my local graveyard, there are plaques for cremated people ... What if it was like that, a shelter attached to the graveyard where there is a placard for graves that are located in other graveyards. If the projection comes alive when people come to it." (\#5). A conversation related to the same topic took the place at the end of the graveside session - [This would be] better as a separate monument, I would never go to the gravestone if there was someone else buried there.(\#2). "There doesn't need to be the physical body." (\#5). "Yeah, [there would be] a separate grave."(\#2). It was also suggested that the projection could be used to make the visit to feel more personal by highlighting your relative's memorial placard amongst a large number of others, "It could darken the lighting on the other cremated people's placards, and light yours up ... and show a slide show. The room would be personalized for you before you enter it."(\#6).

\subsection{Feedback on Visitor Book Concepts}

Generally, the gravestone visitor book concepts were not liked. It was seen 'not proper' to project content such as that on a gravestone, and it was perceived to ruin the atmosphere of the place. Moreover, many concerns related to inappropriate content were raised. For instance, "It would be filled with filth in a moment. Political and bullshit messages." (\#2), "Someone might write something as a joke." (\#5) and "Think about people walking through the graveyard drunk at night, writing messages." (\#6). The visitor book was also commented in respect to existing social media applications, and it was suggested that the guest book could be a site which you accessed through your mobile phone, "There could be a reader next to the gravestone,

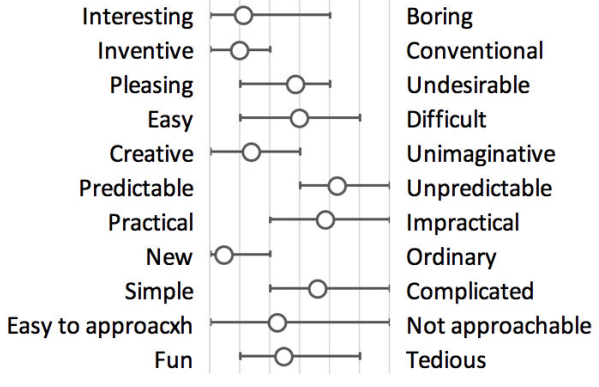

Figure 6: Focus group AttrakDiff evaluation, showing minimum, mean and maximum responses

that would take you to a site or app where you could sign a private guestbook [taps her phone in the hand]. Maybe it could be open for relatives only." (\#1). In case of a grave of some famous person, which was visited by crowds and fans, it was discussed that there could be a place to leave (digital) messages in the proximity of the grave, but not exactly on the gravestone.

The concept of an Artificial Intelligence (AI) representing the dead person and answering the visitor's messages was considered hilarious and provoked laughter. The idea was seen absurd, and even if realized, not belonging to the graveyard context, "Like that one Black Mirror [science fiction show] episode."(\#4) and, "Rather a robot than a graveyard." (\#5). It was also pondered if the concept would have a negative effect on the mourners, as "Can the family and relatives let go of the person, if it writes back?" (\#1). Interestingly, the concept provoked comments where it was perceived as a prison for the dead, or not allowing him/her to rest, "Like a ghost" (\#7), and "isn't it unethical to put it [the personality of the dead] in a gravestone, so it would never get away again?" (\#5).

\subsection{End Questionnaire Results}

The written feedback collected after the outdoor session supported the comments verbalized at the staged graveside. Altogether, $7 / 8$ participants stated that they found the concept interesting and saw good points in it, whereas $1 / 8$ simply stated that the concept was controversial. Half the participants, $4 / 8$ also suggested that it should be implemented as a memorial, not as a gravestone. The result of the Attrakdiff ratings are illustrated in Figure 6. The highest ratings were given to the terms interesting, inventive, and new. Whilst on the other hand, the concept was seen as unpredictable, impractical and complicated.

When the participants were asked to name their least favourite concepts, the guest book and especially the AI part of it was the most disliked idea (4/8), followed by the 'slide show' of information views (3/8). Selecting a favourite concept raised more diverse opinions. The initial, simple concepts without changing pictures were liked the most (by 4/8), but also photos and family tree information were seen as interesting. An interactive grave of a famous people, and a guestbook were each the favourite of one person. 


\section{DISCUSSION}

\subsection{The Importance of Dignity}

Perhaps the most important factor that was brought up throughout the study was that the design, both at conceptual and physical levels, should be dignified. Graves, and any representations of graves, should be treated as respected objects. Our study participants unanimously agreed that graveyards were places where the atmosphere was important, where the dead, their memory and their rest was respected. Our findings indicate that any digital implementations in this domain need to uphold the values characteristics of traditional designs, e.g. dignity and perceived longevity of gravestones. This applies to all aspects of the design and content, for example even the visual transitions between different content views need careful design. Even though we focused on the outlook and design of our interactive gravestone, this was not sufficient, and finding an ideal combination of traditional, tangible and intangible design elements will require more iterations.

\subsection{Gravestones as Information Displays}

Whereas the photos and family history information was perceived as interesting, the participants did not favour of displaying this information on a grave itself. Adding photos was seen to make the visiting experience more personal, and knowing more of distant relatives was perceived interesting and facilitating connection across different generations. The possibility of presenting additional information was envisioned to fit better with an additional memorial, either next to the gravestone or as a separate installation or room, rather than directly on the gravestone. Additional information was especially desired in the context of cemeteries crowded with the dead, where each of the deceased has only a small plaque. This type of setting would be interesting to study further with refined designs, as such places commonly exist in large cities. Moreover, in different cultures, traditions related to graves may be less concerned with concepts such as solitude and peace, which were central issues raised by our user study group.

\subsection{Reflections on Digital Legacy}

Considering our concept of a gravestone-based digital guestbook, participants predominantly suggested ideas resembling existing solutions and practises in the online world e.g. in Facebook. This is particularly relevant, as prior work on online memorials has highlighted the influence of platform features on participation [25]. Public comments were not appreciated in the graveyard context, where it was emphasized that the comments should be respectful Still, as online environments have become new sites for mourning [5], studies connecting physical and digital places of mourning are called for. As there already are digital services where one can set up a virtual grave, e.g. [9], it would be of interest to further study differences in perceptions of digital and physical graveyard designs.

\subsection{Methodological Notes}

Although a main target of our gravestone prototype was to as closely as possible resemble a stone gravestone and its setting, which we consider achieved reasonably well, our study participants immediately perceived it as fake. This highlights methodological issues with the use of such design probes in sensitive contexts. With an alternative approach, where participants were firstly introduced to prior solutions in the area of digitizing graveyards, such as tablet screens embedded in gravestones [14, 29], the focus of discussion may have been different. As our findings exposed our study participant's sensitivities to the graveyard context, we believe our staged environment was to some degree effective in recreating the atmosphere of a real graveyard. We hoped to gain feedback on our use of tangible RFID cards to interact with the gravestone, which could also be carried with the user as a constant reminder in their daily life. However, the overall novelty of the solution for study participants was so great that such details were lost.

\subsection{Limitations and Future Work}

The technical limitations of our prototype include reduced visibility of the projected content in a daylight, and the anticipated short lifetime of such technical implementations. Although the former can be addressed in commercial implementations using alternative technologies, the later highlights a fundamental gap between stone and electronics. We acknowledge that our research is limited by its small sample size, limited age group, and the homogeneous cultural background of the participants. However, we believe our findings provide interesting insights to the under-explored area of integrating digital technologies with the rituals and contexts surrounding the deceased.

As future work, we plan to extend our study to include more diverse participants and different cultures. We speculate that older participants $(60+)$ may be more practicality driven and open to novel solutions in the graveyard context than their younger counterparts. We also aim to refine the design further, and link the concept with a larger cultural heritage site.

\section{CONCLUSION}

In this paper, we have presented a design, implementation and evaluation of an interactive gravestone, which aims to blend in seamlessly with traditional stone gravestones. The concept prototype was evaluated with a focus group session at a staged graveyard, which resulted rich feedback on the desired design and possibilities with the concept. The concept of an interactive gravestone was perceived interesting, but preferably when linked with a memorial than a gravestone marking a burial. Photographs and family history information were positively perceived and seen to have potential to connect across generations, whereas digital guestbook and conversation concepts were not considered suitable for the graveyard context. As design considerations, our findings highlight that the graveyard is a context rich with emotion and rituals, which should be respected in the design. The feeling of authenticity and dignity should be emphasized in the presentation.

\section{ACKNOWLEDGEMENTS}

The work has been partially supported by the European Union's Horizon 2020 Programme under ERCEA grant number 760973 DecoChrom, and Lapland Experience Technologies 2025 project funded by European Regional Development Fund ERDF. 


\section{REFERENCES}

[1] Death Is a High-Tech Trip in Japan's Futuristic Cemeteries. [n. d.]. https://motherboard.vice.com/en_us/article/9a3a5a/ death-is-a-high-tech-trip-in-japans-futuristic-cemeteries. 2019-02-20.

[2] Florian Alt, Thomas Kubitza, Dominik Bial, Firas Zaidan, Markus Ortel, Björn Zurmaar, Tim Lewen, Alireza Sahami Shirazi, and Albrecht Schmidt. 2011. Digifieds: insights into deploying digital public notice areas in the wild. In Proceedings of the 10th International Conference on Mobile and Ubiquitous Multimedia. ACM, $165-174$.

[3] Jed R. Brubaker and Vanessa Callison-Burch. 2016. Legacy Contact: Designing and Implementing Post-mortem Stewardship at Facebook. In Proceedings of the 2016 CHI Conference on Human Factors in Computing Systems (CHI '16). ACM, New York, NY, USA, 2908-2919. https://doi.org/10.1145/2858036.2858254

[4] Jed R Brubaker and Gillian R Hayes. 2011. We will never forget you [online]: An empirical investigation of post-mortem MySpace comments. In Proceedings of the ACM 2011 conference on Computer supported cooperative work. ACM, 123-132.

[5] Jed R Brubaker, Gillian R Hayes, and Paul Dourish. 2013. Beyond the grave: Facebook as a site for the expansion of death and mourning. The Information Society 29, 3 (2013), 152-163.

[6] Candi K Cann. 2013. Tombstone Technology: Deathscapes in Asia, the UK and the US. In Digital legacy and interaction. Springer, 101-113.

[7] Altered Carbon. [n. d.]. https://en.wikipedia.org/wiki/Altered_Carbon. Accessed: 2019-02-20.

[8] Future Cemetery. [n. d.]. http://www.react-hub.org.uk/projects/heritage/ future-cemetery/. Accessed: 2019-02-20.

[9] Hongkong VR Cemetery. [n. d.]. http://vrworld.com/2017/11/22/ first-vr-cemetery-solution-overcrowded-hong-kong/. Accessed: 2019-02-20.

[10] Charu Chaudhari, Anjanakshi Prakash, AM Tsaasan, Jed R Brubaker, and Joshua Tanenbaum. 2016. Penseive box: themes for digital memorialization practices. In Proceedings of the TEI'16: Tenth International Conference on Tangible, Embedded, and Embodied Interaction. ACM, 398-403.

[11] Luigina Ciolfi and Daniela Petrelli. 2015. Studying a Community of Volunteers at a Historic Cemetery to Inspire Interaction Concepts. In Proceedings of the 7th International Conference on Communities and Technologies (C\&\#38;T '15). ACM, New York, NY, USA, 139-148. https://doi.org/10.1145/2768545.2768547

[12] Eternime. [n. d.]. http://eterni.me/. Accessed: 2019-02-20.

[13] Stine Gotved. 2015. Privacy with public access: digital memorials on quick response codes. Information, Communication \& Society 18, 3 (2015), 269-280.

[14] Large Screen Grave. [n. d.]. https://www.youtube.com/watch?v=vv99ER2AlOM Accessed: 2019-02-20.

[15] Jonna Häkkilä, Meri-Tuulia Forsman, and Ashley Colley. 2018. Navigating the Graveyard: Designing Technology for Deathscapes. In Proceedings of the 17th International Conference on Mobile and Ubiquitous Multimedia. ACM, 199-204.

[16] Anders Hall, Dragan Bosevski, and Reinell Larkin. 2006. Blogging by the Dead. In Proceedings of the 4th Nordic conference on Human-computer interaction: changing roles. ACM, 425-428.

[17] Marc Hassenzahl, Michael Burmester, and Franz Koller. 2003. AttrakDiff: Ein Fragebogen zur Messung wahrgenommener hedonischer und pragmatischer Qualität. In Mensch \& computer 2003. Springer, 187-196.

[18] Simo Hosio, Jorge Goncalves, Hannu Kukka, Alan Chamberlain, and Alessio Malizia. 2014. What's in it for me: Exploring the real-world value proposition of pervasive displays. In Proceedings of the international symposium on pervasive displays. ACM, 174.

[19] Real Humans. [n. d.]. https://www.imdb.com/title/tt4122068/. Accessed: 2019$02-20$.

[20] Black Mirror I'll be right back. [n. d.]. https://www.imdb.com/title/tt2290780/. Accessed: 2019-02-20.

[21] Sue Jamison-Powell, Pam Briggs, Shaun Lawson, Conor Linehan, Karen Windle, and Harriet Gross. 2016. PS. I Love You: Understanding the Impact of Posthumous Digital Messages. In Proceedings of the 2016 CHI Conference on Human Factors in Computing Systems. ACM, 2920-2932.

[22] Vassilis Kostakos and Timo Ojala. 2013. Public displays invade urban spaces. IEEE Pervasive Computing 12, 1 (2013), 8-13.

[23] Michael Massimi and Ronald M. Baecker. 2010. A Death in the Family: Opportunities for Designing Technologies for the Bereaved. In Proceedings of the SIGCHI Conference on Human Factors in Computing Systems (CHI '10). ACM, New York, NY, USA, 1821-1830. https://doi.org/10.1145/1753326.1753600

[24] David L Morgan. 1996. Focus groups as qualitative research. Vol. 16. Sage publications.

[25] Joji Mori, Martin Gibbs, Michael Arnold, Bjorn Nansen, and Tamara Kohn. 2012. Design considerations for after death: comparing the affordances of three online platforms. In Proceedings of the 24th Australian Computer-Human Interaction Conference. ACM, 395-404.

[26] William Odom, Richard Banks, David Kirk, Richard Harper, Siân Lindley, and Abigail Sellen. 2012. Technology heirlooms?: considerations for passing down and inheriting digital materials. In Proceedings of the SIGCHI Conference on Human Factors in computing systems. ACM, 337-346.

[27] William Odom, Richard Harper, Abigail Sellen, David Kirk, and Richard Banks. 2010. Passing on \& Putting to Rest: Understanding Bereavement in the Context of Interactive Technologies. In Proceedings of the SIGCHI Conference on Human Factors in Computing Systems (CHI '10). ACM, New York, NY, USA, 1831-1840. https://doi.org/10.1145/1753326.1753601

[28] Daisuke Uriu and Naohito Okude. 2010. ThanatoFenestra: photographic family altar supporting a ritual to pray for the deceased. In Proceedings of the 8th ACM Conference on Designing Interactive Systems. ACM, 422-425.

[29] Vidstone. [n. d.]. https://www.youtube.com/watch?v=7Tvfny_rJmY. Accessed: 2019-02-20.

[30] Tony Walter, Rachid Hourizi, Wendy Moncur, and Stacey Pitsillides. 2012. Does the internet change how we die and mourn? Overview and analysis. OMEGAfournal of Death and Dying 64, 4 (2012), 275-302. 